\title{
Exploring Short Video Application Users' Visit Intention: Applying the Stimulus-Organism-Response Model
}

\author{
Mao-Hua $\mathrm{Li}^{1}$ \\ ${ }^{1}$ Department of Economics and Management, Zhanjiang Preschool Education College, Zhanjiang, China \\ Correspondence: Mao-Hua Li. E-mail: T18092105031@cityu.mo
}

Received: July 30, 2019

Accepted: August 12, 2019 Online Published: November 13, 2019

doi:10.5539/ass.v15n12p8

URL: https://doi.org/10.5539/ass.v15n12p8

\begin{abstract}
This paper aims to extend the Stimulus-Organism-Response (S-O-R) model to social media context in China and validate the positive influence between short video, destination image, perceived interactivity, and short video application users' visit intention. Data were collected through an online survey, a PLS-SEM analysis was used. The results $(\mathrm{n}=236)$ show that video quality significantly affects both the cognitive and affective image of the video destination, and the perceived interactivity significantly influences their behavioral intention. This study makes up for the deficiency of the theoretical research of social media and helps tourism departments to develop appropriate promotion strategies to destinations.
\end{abstract}

Keywords: short video application, destination image, perceived interactivity, Stimulus-Organism-Response model, perceived interactivity, user behavior

\section{Introduction}

The continuous improvement of information technology and the accelerated upgrading of mobile terminals have more and more influences on our way of life. The 43rd statistical report on the development of China's Internet shows that by the end of 2018, China had 829 million Internet users and reached 59.6\% penetration, with a 3.8 percent increase than that of 2017 and the number of Internet users increased by 56.53 million in 2018. China has 817 million mobile Internet users, with $98.6 \%$ of them accessing the Internet through mobile phones (CNNIC, 2019). It can be seen that the trend of the mobile phone as the main Internet terminal for Chinese netizens is increasing. In such an era of mobile Internet, people can communicate with each other unimpeded, and the possibility of network information influencing people to make decisions becomes more and more possible. In all forms of information representation, videos and pictures are increasingly prominent, they are important content that people are keen to share with others on social media. The social application user behavior research report of China in 2016, which was released by China Internet Network Information Center (CNNIC) in December 2017, states that social apps have become an important platform for broadcasting video content. 59.4\% of users have Shared or forwarded video programs on social apps, and their video consumption habit has been formed on social apps (CNNIC, 2017). While social applications take advantage of the user relationship chain to drive the spread of video content, video content also feeds back to social applications, thus improving the content richness, interaction frequency and user stickiness of social platforms. Modern young people are proficient in the Internet and smart devices, they are obsessed with social media and spread information quickly. These young people use social media not only for entertainment purposes but also to habitually share their travels and experiences (Wong, 2016).

Tourism literature shows that destination image is the premise of visitor's loyalty, satisfaction, visit intention, revisit intention and destination selection (Alvarez \& Campo, 2014; Choi, Tkachenko, \& Sil, 2011; Kock, Josiassen, \& Assaf, 2016; Mao \& Zhang, 2014). Before the actual visit, different tourists have different impressions of a certain destination. A destination with positive images is more welcomed by tourists than negative ones, therefore, the understanding of destination image is very important for marketers or officials to implement appropriate marketing strategies.

With the continuous expansion of the influence scope of new media technology development, under the development of a new media era, short video application emerged as a new media. The short video lasts for a short time, which can be tens of seconds or 3 to 5 minutes. Based on mobile intelligent terminals or professional devices, individual users or professional teams can quickly shoot, edit and upload them to social media platforms 
such as Douyin, Kuaishou, Weibo and WeChat (Zhang, Wu, \& Liu, 2019). The content of the short video is rich and with a wide range of themes, which can be played free of charge by users and shared with one click. It spreads to more audiences through two ways: information flow and influence flow. In short video apps such as Douyin, Kuaishou, VUE, pear video, Xi'an is famous for attractions named "Great wild goose pagoda", "Terracotta Warriors and Horses", "Lotus palace of Tang dynasty", "The Huaqing Pond" etc., and popular "smash bowl after drink the wine", "steamed cold noodles", "Chinese brush-like pastry", etc.. In terms of social media, scholars have conducted abundant researches on information search, decision-making, information sharing, tourists' intention, and destination image. However, most studies are based on digital footprints, such as online evaluation and online travel records, while few studies are conducted on video social media. Given this, this paper takes Xi'an, a city of internet celebrity, as an example to study the relationship between short video, destination image, perceived interactivity and tourists' visit intention by applying the Stimulus-Organism-Response (S-O-R) model. The results will help tourism departments to develop appropriate strategies to promote tourism and disseminate relevant information that can bring the short video tourism destination closer to the tourists.

\section{Literature Review and Hypotheses}

The S-O-R model may be a useful framework to explore the factors associated with short videos, this paradigm has been used in different situations to explore an individual's decision-making process (Kim \& Lennon, 2013), such as retailing, theme parks, motion pictures, online shopping, etc.. At present, few kinds of literature give contributions to the application of the S-O-R model in the study of the short video.

\subsection{The Stimulus-Organism-Response (S-O-R) Theory}

In 1974, Mehrabian and Russell pioneeringly proposed the Stimulus-Organism-Response (S-O-R) model as shown in Figure 1 (Mehrabian \& Russell, 1974). This model indicates that stimuli can influence an individual's emotional states, and then influence an individual's behavior, which shows in two ways: approach or avoidance. Approach behavior is willing to do, while avoidance behavior is the opposite.

\begin{tabular}{|c|c|c|}
\hline $\begin{array}{c}\text { Environmental } \\
\text { stimuli }\end{array}$ & $\longrightarrow \begin{array}{c}\text { Emotional states: } \\
\text { Pleasure, Arousal, Dominance }\end{array}$ \\
\cline { 1 - 2 } Stimulus & Organism & $\begin{array}{c}\text { Response Behaviors: } \\
\text { Approach/Avoidance }\end{array}$ \\
\hline
\end{tabular}

Figure 1. The Stimulus-Organism-Response (S-O-R) Model (Mehrabian \& Russell, 1974)

The antecedent variable in the model is the stimulus, which refers to the factors in the environment that stimulate and promote human action, including all the information that can be sensed by the human sensory organs. It is also a driving force in the environment that may influence consumers' cognitive and emotional processes. The organism, which is composed of perceptual, psychological, sensory and thinking activities, is the mediator between the environmental stimuli and response behaviors. According to Russell (1978), emotional states can be divided into three aspects, say, pleasure, arousal, and dominance; Cognitive concepts include perceived risk, perceived value, perceived information, and trust. The response variable shows an individual's behavior towards their emotional states, it is the psychological or behavioral response (Russell, 1978).

The S-O-R model is widely applied in marketing, especially in online shopping. Yun and Good (2007) established a model in which a good e-tail store image will have a positive impact on customers' e-patronage intention and then e-loyalty will be generated. Under the same inspiration, Hsu and Tsou (2011) used the S-O-R model to discuss the impact of website quality on consumer's emotions and the impact of emotion on repurchase intention. See Figure 2.

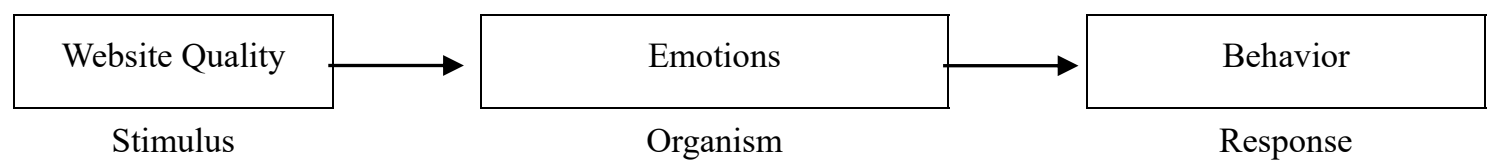

Figure 2. An S-O-R model of consumer response to website quality (Hsu \& Tsou, 2011)

In the field of tourism, the S-O-R model has been introduced by the theory of environmental psychology to study the influence of tourism environment and media on the response of potential tourists. As a kind of social activity, tourism is also an experience and people's behavior will be affected by outside factors. Many tourism advertisements, videos, and television programs are treated as a stimulus to arouse the resonance of cognitive 
and affective ways by the audience and then generate the visit intention. Inspired by the above, this paper takes the short video as the stimulus to stimulate potential tourists' perceived image and value of tourism destination and generate the intention of going out for tourism.

\subsection{Destination Image}

The existing literature defined the destination image as an individual's mental representation of knowledge (beliefs), feelings and overall perception of a particular destination (Crompton, 1979; Fakeye \& Crompton, 1991). The destination image originated from tourists' cognitive and affective evaluation. Cognitive evaluation is what a tourist knows, affective evaluation is how a tourist feels. The cognitive image refers to the sum of beliefs and knowledge that reflect the evaluations of the perceived attributes of the destination (Alcañiz, García, \& Blas, 2009; Stylos \& Andronikidis, 2013; Zhang, Fu, Cai, \& Lu, 2014). The affective image refers to the individual's emotional response or evaluation, which reflects the tourists' feelings towards the destination (Baloglu \& McCleary, 1999; Bigné, Andreu, \& Gnoth, 2005; Hallmann, Zehrer, \& Müller, 2015). Examples of cognitive evaluation are attractiveness, local characteristics, value for money, and gastronomy. Pleasure and arousal are examples of affective evaluation.

Although cognitive dimension and affective dimension are considered as important components of tourism image, some existing researches on tourism image only consider the cognitive dimension and ignore the affective dimension (Sameer Hosany, Ekinci, \& Uysal, 2006). However, recent research has shown that the destination image is better understood when both cognitive and affective dimensions are considered. Therefore, to gain insight into how tourists rate a destination, the cognitive and affective aspects should be studied separately (Russell \& Pratt, 1980; Stylos, Vassiliadis, Bellou, \& Andronikidis, 2016).

\subsection{Perceived Interactivity}

Researchers began to study the concept of interactivity in the 1980s (Wu \& Wu, 2006). Interactivity can be classified into the following two categories (Hoffman \& Novak, 1996): user-to-user, which focused on the responsiveness to the content posted by a user; and user-to-system, which focuses on the technological characteristics (Zhao \& Lu, 2012). According to the telepresence theory, the power of media affects the user's perception of interactivity (Steuer, 1992). Besides, previous empirical studies show that there is a positive correlation between perceived interaction and behavioral intention (McMillan \& Hwang, 2002). Based on the extant research, we define the perceived interactivity as the perceptions of feeling and benefits that users experience when watching a short video. Users interact with video sites by watching short videos, and various functions of video sites may affect users' psychological process of sharing and using intention. Video sites provide the "sharing" function, which allows users to link and publish videos to social network sites (e.g., Facebook, WeChat, and Weibo). For example, Douyin, the most popular mobile social short video app in China, allows the sharing of short videos by downloading the video first and then shared with any available sites. Once shared on other social media, the videos have the potential to be disseminated quickly and viewed by many individuals (Guo, Huang, He, Hei, \& Wu, 2013). Hence, "sharing" behavior is beneficial for disseminating the destination because it is conducive to attracting more viewers who watched the videos. Therefore, we present the following hypotheses:

H1. The cognitive image is positively related to the perceived interactivity of a destination in social short video media.

H2. The affective image is positively related to the perceived interactivity of a destination in social short video media.

H3. Perceived interactivity is positively related to the visit intention of tourists.

\subsection{Short Video Apps and Destination Image}

Compared with text content, pictures and video in social media can more directly and vividly convey the destination image. At present, the research on destination image based on comments, travel notes and pictures is relatively mature, and the research on the influence of microfilms and propaganda films on destination image is increasingly active. With the help of psychological experiments, Tessitore, Pandelaere, and Van Kerckhove (2014) found that reality shows can affect people's perception of cognitive image and affective image. Spencer (2013) confirmed that watching short video films about the tourism destination image has a powerful effect on the spread of destination attraction. Woodside and Dubelaar (2002) found that tourism video advertising would influence tourists to form a positive cognitive image and significantly increase their tourism expenditure. The association between motion pictures and tourism has created tourism concepts such as film-induced tourism/film tourism (Beeton, 2001), movie-induced tourism (Riley, Baker, \& Van Doren, 1998), media tourism (Busby \& 
Klug, 2001), screen-tourism (Connell \& Meyer, 2009; Kim, Long, \& Robinson, 2009) and Hallyu (Lee \& Bai, 2010). In conclusion, as a way for tourists to understand the destination image, the video has a significant impact on the destination image. Creative video released by users on short video social media not only meets social needs but also has certain publicity and influence on video subjects. Taking Xi 'an as an example, the short video uploaded by users spontaneously about "Terracotta warriors and horses", "Lotus palace of Tang dynasty", "smash bowl after drink the wine", "steamed cold noodles", "Chinese brush-like pastry" etc. updated tourists' stereotypes of Xi'an and generated positive image cognition. It can be seen that a short video is an important carrier affecting the image perception of potential tourism destinations. The influence of short video on destination image can be reflected in three aspects. One is the cognitive level. Video audiences will pay attention to a certain tourism destination because they frequently see these videos. Secondly, at the level of consciousness, video audiences will decode the information in the video to judge whether the place has tourism value. Thirdly, the decision-making level, video information will drive the audience to make tourism decisions. The quality and credibility of a video are the most important factors that affect the audience's concern to the tourism destination, therefore, this paper divides short video construct into video quality and video credibility. The generation of the destination image is a process of subjective perception and the result of individual psychological mechanism's processing of stimuli, including cognitive image and affective image. Therefore, this paper proposes the following hypotheses:

H4a. The video quality of the short video App is positively related to tourists' perception of the cognitive image of a tourism destination.

H4b. The video quality of the short video App is positively related to tourists' perception of affection image of a tourism destination.

H5a. The video credibility of short video App is positively related to tourists' perception of the cognitive image of a tourism destination.

H5b. The video credibility of short video App is positively related to tourists' perception of the affective image of a tourism destination.

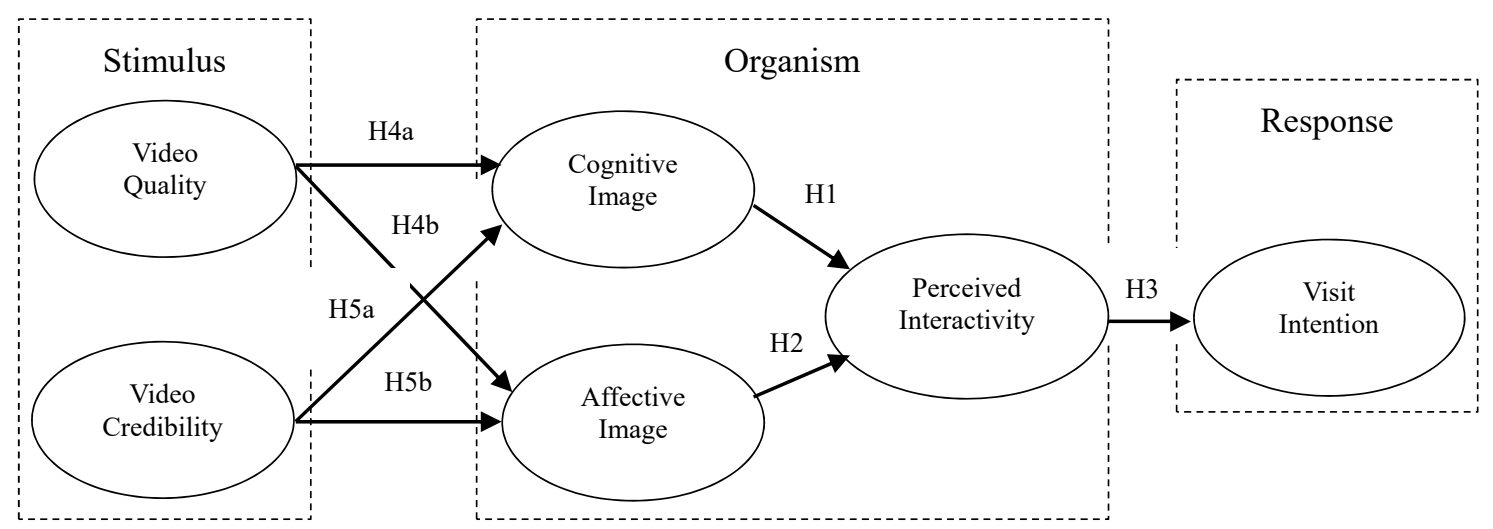

Figure 3. The conceptual model

\section{Research Design}

There are two questions to study in this paper: (1) Can short video arouse the resonance of the tourists toward tourist destination and generate the visit intention? (2) Whether video quality and video credibility of short video apps have the same impact on users' perception of destination image? The questionnaire survey was conducted to determine the influence of short video on users' visit intention. The questionnaire was divided into two parts. The first part was questioned about the model dimensions. The second part deals with general background information.

\subsection{Instrument}

The scale used for measurement was mainly derived from previous studies and modified according to the test set. according to test scenarios. The 22 measurable items for the six constructs were shown in Table 2. The dimensions of video quality and video credibility were adapted from Bhattacherjee and Sanford (2006), whereas the items related to cognitive image and affective image were adapted from Stylos et al. (2016). The measured items for perceived interactivity were adapted from Liu, Suh, and Wagner (2016), and the measured items for visit intention were adapted from Han, Lee, and Lee (2011). A seven-point Likert scale was used to measure all 
the items, respondents need to choose an answer from (1) "strongly disagree" to (7) "strongly agree". The online survey was conducted in China, so the questionnaire was translated into Chinese. The final version was checked by two university professors of marketing and tourism, to minimize discrepancies in meaning or syntax and meet the content validity. After that, a pilot test invited 20 Chinese citizens who have experiences of using short video applications to answer the survey. The participants said that all the contents in the survey were clear and easy to understand.

\subsection{Data Collection}

The online survey was conducted through the professional online survey website (www.wjx.cn) in China. The questionnaire was first published on the website, and then made into a QR code picture, sent to the QQ group or WeChat group for answering. A total of 251 questionnaires were collected, however, 15 of them were discarded due to incomplete or invalid information, resulting in a final sample consisting of 236 valid responses. Only users who are using or have used the short video Apps are available to answer the questionnaire.

\section{Findings}

To test our hypothesized research model, we employed structural equation modeling using the partial least squares (PLS) analysis, because this method is more suitable for exploratory studies and small sample size (Chin, Marcolin, \& Newsted, 2003; Fornell \& Bookstein, 1982). In the partial least square method, the structure model is estimated by an iterative method, which strengthens the relationship between independent variables and dependent variables (S. Hosany \& Martin, 2012). In addition, the PLS method shows a larger convergence in its simplicity and less limitation on the normality of data (Chin et al., 2003). Therefore, the PLS analysis was suitable for this research and SmartPLS V.3.2.8 software was used.

\subsection{Respondent Demographics}

Table 1 shows the demographics of valid questionnaires. Female respondents were slightly more than male respondents $(56.8 \%)$. The short video apps users are mostly among young generations (18-25 years old), individuals over 45 years old also use short video apps (9.3\%). Most of the participants were diploma-level graduates $(51.3 \%)$, few of them were under secondary level or lower $(1.3 \%)$. The monthly income after tax mostly less than RMB3000 (55.9\%), this is due to their students' status. Although more than half of the participants were students and teenagers, this group made up the majority of mobile short video application users. The sample composition was consistent with the population distribution of Chines social application users reported by CNNIC (2017). From the investigation, we also find that most of the short video application users were inclined to travel with friends or family members $(83.5 \%)$, only $11.9 \%$ of the respondents preferred to travel alone.

Table 1. Demographics of respondents $(\mathrm{n}=236)$

\begin{tabular}{|c|c|c|c|}
\hline & & Frequency & Percentage $(\%)$ \\
\hline \multirow{2}{*}{ Gender } & Male & 102 & 43.2 \\
\hline & Female & 134 & 56.8 \\
\hline \multirow{4}{*}{ Age } & $18-25$ & 163 & 69.1 \\
\hline & $26-35$ & 51 & 21.6 \\
\hline & $36-45$ & 15 & 6.4 \\
\hline & 46 or over & 7 & 2.9 \\
\hline \multirow{5}{*}{ Education } & Secondary level (or lower) & 3 & 1.3 \\
\hline & Secondary school graduate & 4 & 1.7 \\
\hline & College graduate (Diploma-level graduate) & 121 & 51.3 \\
\hline & Bachelor-level graduate & 85 & 36.0 \\
\hline & Master-level graduate (or higher) & 23 & 9.7 \\
\hline \multirow{4}{*}{$\begin{array}{l}\text { Monthly income (RMB) } \\
\qquad \text { (after tax) }\end{array}$} & less than 3,000 & 132 & 55.9 \\
\hline & $3,001-5,000$ & 26 & 11.0 \\
\hline & $5,001-10,000$ & 63 & 26.7 \\
\hline & 10,001 or over & 15 & 6.4 \\
\hline \multirow{4}{*}{ Career } & Full-time student & 148 & 62.7 \\
\hline & employee & 66 & 28.0 \\
\hline & Unemployed/retired & 8 & 3.4 \\
\hline & Other & 14 & 5.9 \\
\hline
\end{tabular}




\begin{tabular}{cccc}
\hline & alone & 28 & 11.9 \\
travel habits & Package tour & 11 & 4.7 \\
& With friends or family & 197 & 83.5 \\
\hline
\end{tabular}

\subsection{Reliability and Validity}

Table 2 shows the means, standard deviation, Cronbach's alpha, PLS loadings, Construct Reliability (CR), and Average Variance Extracted (AVE) values of the research model. The Cronbach's alpha of each construct exceeds 0.80 indicates good internal consistency. The CR values of each construct were from 0.91 to 0.97 and the AVE values all exceed 0.50 . The PLS loading of each indicator on its construct is higher than the cross-loadings on other constructs (Hair Jr, Sarstedt, Hopkins, \& Kuppelwieser, 2014). In addition, two different statistical techniques were used, including the traditionally-used Fornell and Larcker (1981) procedure and the newly-introduced heterotrait-monotrait ratio of correlations (Henseler, Ringle, \& Sarstedt, 2015). As heterotrait-monotrait ratio refers to the degree to which each construct does not replicate any other construct, it can be determined by establishing a low correlation between a construct of interest and all other constructs (Molinillo, Liébana-Cabanillas, Anaya-Sánchez, \& Buhalis, 2018). Table 3 shows the square root of AVE is greater than its correlation coefficients with other constructs, indicating satisfactory discriminant validity (Gefen, Straub, \& Boudreau, 2000). Table 3 also shows that all values of the heterotrait-monotrait ratio were lower than the threshold of 0.90 , reinforcing the satisfactory discriminant validity for all constructs in this study.

Table 2. Reliability and Construct Validity.

\begin{tabular}{|c|c|c|c|c|c|c|c|}
\hline & Measure item & Mean & $\begin{array}{l}\text { Std. } \\
\text { Dev. }\end{array}$ & $\begin{array}{l}\text { Cronbach's } \\
\text { alpha }\end{array}$ & $\begin{array}{c}\text { factor } \\
\text { loadings }\end{array}$ & AVE & $\mathrm{CR}$ \\
\hline VQ & Video Quality & 4.657 & & 0.854 & & 0.772 & 0.910 \\
\hline VQ1 & The short video has a clear picture. & 4.814 & 1.228 & & 0.903 & & \\
\hline VQ2 & The short-video was informative. & 4.716 & 1.235 & & 0.919 & & \\
\hline VQ3 & The information offered by short video was valuable. & 4.441 & 1.183 & & 0.811 & & \\
\hline $\mathrm{VC}$ & Video Credibility & 4.145 & & 0.877 & & 0.802 & 0.924 \\
\hline $\mathrm{VC} 1$ & The short videos were credible. & 4.093 & 1.085 & & 0.933 & & \\
\hline $\mathrm{VC} 2$ & The short videos were knowledgeable. & 4.322 & 1.278 & & 0.890 & & \\
\hline $\mathrm{VC} 3$ & The short videos about Xi'an were trustworthy. & 4.021 & 1.133 & & 0.862 & & \\
\hline $\mathrm{CI}$ & Cognitive Image & 5.172 & & 0.958 & & 0.828 & 0.967 \\
\hline CI1 & Xi'an has beautiful landscapes. & 4.992 & 1.207 & & 0.880 & & \\
\hline $\mathrm{CI} 2$ & Xi'an has a precious historical and cultural heritage. & 5.335 & 1.208 & & 0.931 & & \\
\hline $\mathrm{CI} 3$ & $\mathrm{Xi}$ 'an has a unique culture and customs. & 5.301 & 1.171 & & 0.957 & & \\
\hline CI4 & $\mathrm{Xi}$ 'an has an attractive variety of local gastronomy. & 5.297 & 1.199 & & 0.945 & & \\
\hline CI5 & Xi'an has a variety of recreational facilities. & 4.919 & 1.174 & & 0.825 & & \\
\hline CI6 & Xi'an has a strong tourism atmosphere. & 5.186 & 1.171 & & 0.917 & & \\
\hline AI & Affection Image & 5.074 & & 0.959 & & 0.890 & 0.970 \\
\hline AI1 & Unpleasant----pleasant & 5.059 & 1.251 & & 0.944 & & \\
\hline AI2 & Gloomy -----Exciting & 5.059 & 1.181 & & 0.933 & & \\
\hline $\mathrm{AI} 3$ & Distressing-----Relaxing & 5.072 & 1.179 & & 0.951 & & \\
\hline AI4 & Boring ----- Fun & 5.106 & 1.190 & & 0.945 & & \\
\hline PI & Perceived interactivity & 7.792 & & 0.905 & & 0.840 & 0.940 \\
\hline PI1 & When watching Xi'an videos, I was full of imagination. & 4.818 & 1.092 & & 0.914 & & \\
\hline PI2 & $\begin{array}{l}\text { When watching Xi' an videos, I benefited from the user } \\
\text { community. }\end{array}$ & 4.716 & 1.105 & & 0.930 & & \\
\hline PI3 & $\begin{array}{l}\text { When watching Xi'an videos, I can get useful } \\
\text { information from other users' videos. }\end{array}$ & 4.843 & 1.056 & & 0.906 & & \\
\hline VI & Visit intention & 5.049 & & 0.952 & & 0.912 & 0.969 \\
\hline VI1 & In recent years, if I plan for a trip, I will visit Xi'an. & 4.966 & 1.248 & & 0.958 & & \\
\hline VI2 & $\begin{array}{l}\text { If I have a chance to travel, I will consider a trip to } \\
\mathrm{Xi} \text { 'an. }\end{array}$ & 5.025 & 1.231 & & 0.961 & & \\
\hline VI3 & In short, I think Xi'an is a good place deserving visit. & 5.157 & 1.216 & & 0.947 & & \\
\hline
\end{tabular}

Notes: AVE: average variance extracted and CR: composite reliability. 
Table 3. Discriminant Validity

\begin{tabular}{|c|c|c|c|c|c|c|}
\hline \multicolumn{7}{|c|}{ Fornell-Larcker criterion } \\
\hline & AI & $\mathrm{CI}$ & PI & $\mathrm{VC}$ & VI & VQ \\
\hline AI & 0.943 & & & & & \\
\hline $\mathrm{CI}$ & 0.515 & 0.910 & & & & \\
\hline PI & 0.600 & 0.634 & 0.917 & & & \\
\hline $\mathrm{VC}$ & 0.311 & 0.467 & 0.535 & 0.895 & & \\
\hline VI & 0.537 & 0.645 & 0.729 & 0.404 & 0.955 & \\
\hline VQ & 0.420 & 0.601 & 0.598 & 0.715 & 0.467 & 0.879 \\
\hline \multicolumn{7}{|c|}{ Heterotrait-Monotrait ratio } \\
\hline \multicolumn{7}{|c|}{ AI } \\
\hline CI & 0.537 & & & & & \\
\hline PI & 0.643 & 0.681 & & & & \\
\hline $\mathrm{VC}$ & 0.337 & 0.503 & 0.595 & & & \\
\hline VI & 0.562 & 0.675 & 0.784 & 0.437 & & \\
\hline VQ & 0.455 & 0.652 & 0.674 & 0.827 & 0.509 & \\
\hline
\end{tabular}

Note: $\mathrm{VQ}=$ video quality; $\mathrm{VC}=$ video credibility; $\mathrm{CI}=$ cognitive image; $\mathrm{AI}=$ affective image; $\mathrm{PI}=$ perceived interactivity; $\mathrm{VI}=$ visit intention; Numbers in bold: square root of the AVE.

\subsection{Results}

A Bootstrap procedure was used with 236 cases and 5000 samples to test the significance of the path coefficients and all the loadings. In addition to these standard methods, Hair, Ringle, and Sarstedt (2013) recommended reporting the effect sizes $\left(\mathrm{f}^{2}\right)$ for each relationship in the structural model. Figure 4 shows the results of the PLS analysis. Form the figure we know that $\mathrm{H} 1, \mathrm{H} 2, \mathrm{H} 3, \mathrm{H} 4 \mathrm{a}, \mathrm{H} 4 \mathrm{~b}$ are supported, both of them have significantly related to each other. $\mathrm{H} 5 \mathrm{a}$ and $\mathrm{H} 5 \mathrm{~b}$ are unsupported suggest that video credibility is not significantly related to users' perception of tourist destination image (see Table 4). Next, we assessed the effect sizes. Hair et al. (2013) suggested reporting both substantive significance $\left(\mathrm{f}^{2}\right)$ and statistical significance $(\mathrm{p})$. To measure the effect size, we used Cohen (2013) guidelines - 0.02 for small effects, 0.15 for medium effects, and 0.35 for large effects. Table 4 shows that video quality, cognitive image, and affective image had a medium effect size, perceive interactivity had a large effect size, whereas video credibility had no effect.

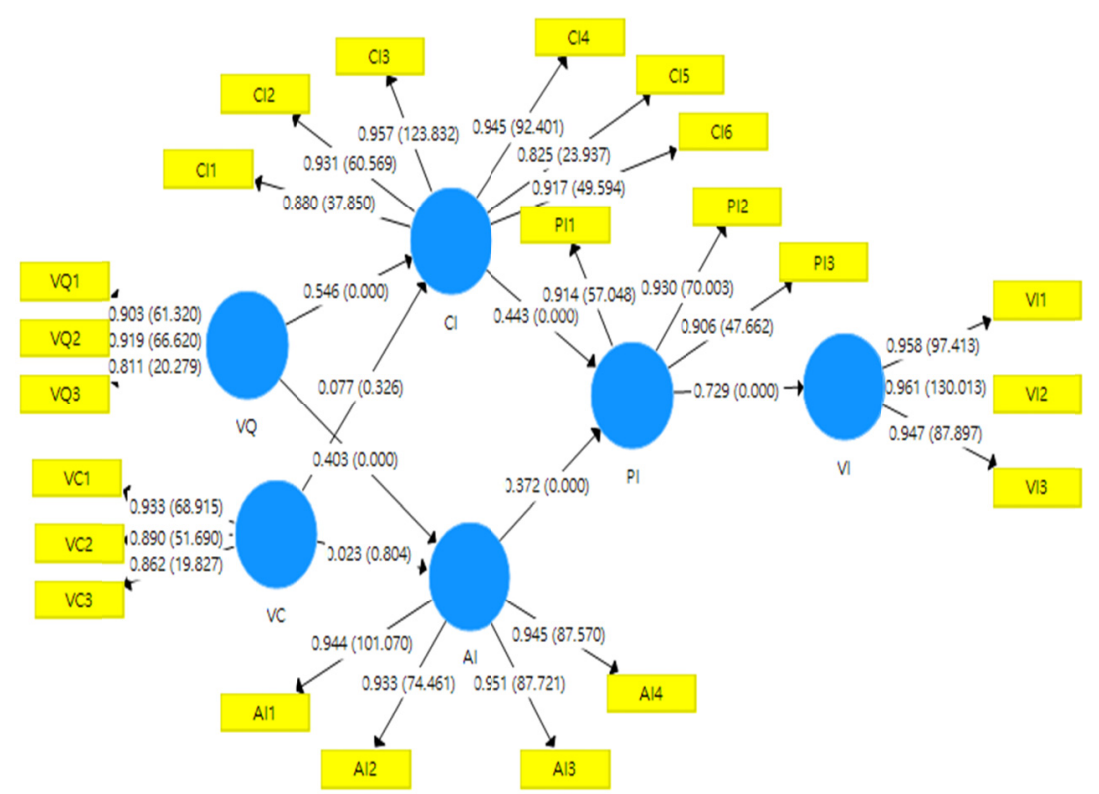

Figure 4. Results of the PLS analysis 
Table 4. Structural Estimates (Hypotheses Testing)

\begin{tabular}{cccc}
\hline Hypotheses & T Value & Decision & F Square \\
\hline H1: CI - > PI & $4.222^{* * *}$ & Supported & 0.290 \\
H2: AI - > PI & $3.969^{* * *}$ & Supported & 0.205 \\
H3: PI - > VI & $17.248^{* * *}$ & Supported & 1.132 \\
H4a: VQ - > CI & $7.205^{* * *}$ & Supported & 0.230 \\
H4b: VQ - $>$ AI & $4.18^{* * *}$ & Supported & 0.096 \\
H5a: VC $>$ CI & 0.983 & Not Supported & 0.005 \\
H5b: VC $>$ AI & 0.248 & Not Supported & 0.000 \\
\hline
\end{tabular}

Note: $* p<0.05 ; \quad * * p<0.01 . * * * p<0.001$.

\section{Discussions}

The results revealed the significant impact of short video quality on user's cognitive and affective image to their perceived interactivity with the destination places, indicating that short videos are indeed impacting mobile user's intention to travel. This study identified potential visitors' cognitive and affective responses to short video content and visit intention to the destination presented in the short videos. This study sheds light on why short video app users want to visit the destination shown in short videos and provides implications for academics and practitioners.

\subsection{Contribution to Theory}

Many scholars study the image of tourist destinations, mostly researching the relationship between cognitive image, affective image, and overall image. This paper innovatively introduces the perceived interactivity variable to replace the overall image, confirms the three-dimensional structure of destination image, and the cognitive image and affective image are positively correlated with the perceived interactivity of short video app users. The research results are the confirmation of the previous theory of destination image, say, the destination image is divided into two dimensions: cognitive image and affective image, which jointly affect the overall image. The research results are also the innovation of the original theory, we verified that the perceived interactivity plays a positive role in the travel intention of short video users.

Short video quality can not only positively affect short video app users' perception of destination cognitive image, but also positively affect their perception of destination affective image. The higher the quality of the video, the more comprehensive, accurate, interesting, unique and appropriate the destination information it conveys, and the more potential users can have a profound understanding of the resource attributes of the destination, thus generating a better cognitive image perception of the destination. In addition, high-quality video often has a strong sense of the scene, which can create a strong tourism atmosphere and stimulate the imagination of potential tourists. The heart-pounding spiritual feeling can make potential tourists have a pleasant feeling towards the destination and positively affect their perception of the affective image of the destination. When video released on short video software becomes popular, it will constantly refresh the viewers' cognition of the destination image, stimulate the viewers' psychology of confirming the destination, and at the same time, the psychology of seeking novelty and difference will prompt tourists to make decisions. It should be noted that users do not care about the credibility of the source of the short video, because they can judge whether something is true or not from its video quality. Therefore, the credibility of the video source has no impact on users' perception of the destination image.

From the existing literature, scholars' research on video media largely ignored the important factor of perceived interactivity. Although the importance of continuous use and instantaneous sharing for the website has been addressed by researchers (Lai \& Wang, 2009; Wangpipatwong, Chutimaskul, \& Papasratorn, 2008; Zhao \& Lu, 2012), the correlation between perceived interactivity and destination visit intention has not been taken into account. The research results of this paper show that perceived interactivity will affect the willingness of short video users to share video, as well as their willingness to visit the destination. Therefore, we can say that perceived interactivity is a clear variable in the study of short video social media, which reflects the essence of audience interaction in short video applications.

\subsection{Implications for Practice}

Tourism destinations should make full use of short video social media resources to expand their popularity and influence. A short video with high quality can significantly affect tourists' cognitive image and affective image, 
and indirectly affect tourists' travel intention. It is of great significance to maintain the relationship between tourists and destinations and enhance their loyalty to destinations. At present, popular social short video app--Douyin software is one of the important communication channels of the destination image. In the real marketing process, destinations need to strengthen cooperation with this kind of software, broaden the channels of publicity. Besides, audiences of social short video apps such as Douyin are younger generations and they are more likely to accept external stimuli and make tourism behaviors. Therefore, the use of a social short video app in destination marketing is an important way to attract young tourists and maintain the attraction.

Destination marketing should be innovative. From the videos of Douyin short video app, we can know that "internet celebrity" products are more interesting to users. Xi'an, the ancient capital of 13 dynasties with profound history and culture, has become a stereotype. Therefore, by combining with "internet celebrity", more tourists can come for an in-depth experience. Videos such as "Terracotta warriors and horses", "Smash bowl after drink the wine", "steamed cold noodles", "Chinese brush-like pastry" etc. in social media are typical cases of successful marketing for Xi'an city, which also play an important role of contributing to Xi'an's effective image marketing.

Tourist destinations should do a good job in tourism market construction and environmental optimization. Only when tourists experience the perfect infrastructure and good atmosphere in the destination, can they form a good cognitive image and affective image, and have a positive influence on revisiting and recommendation. Therefore, when marketing the destination, we should always pay attention to the optimization of the market and environment.

\subsection{Limitations and Further Research}

The limitations of this study are as follows. First of all, this study only verified the visit intention of Chinese short video social media users, so it could not be extended to other media in China or video media in other countries. Therefore, future research can compare the visit intention generated by other media or media users in other countries.

Second, the majority of our survey respondents were students, they may have a different perception of destination image compared with old generations, thus users with varied experiences may have a different attitude toward visit intention. Future studies can improve generalizability by using more different aged and career samples.

Finally, the short video is a dynamic thing. Future studies can explore the impact of static visual objects (pictures of tourist destinations, etc.) on an individual's tourism visit intention, which may have new findings.

\section{Acknowledgment}

Fund project: Zhanjiang Preschool Education College General Project (No. ZJYZYB201703). Teaching Reform Project of Guangdong Provincial Higher Vocational Education Management Major Teaching Steering Committee (No. YGL201885).

\section{References}

Alcañiz, E. B., García, I. S., \& Blas, S. S. (2009). The functional-psychological continuum in the cognitive image of a destination: A confirmatory analysis. Tourism Management, 30(5), 715-723. https://doi.org/10.1016/j.tourman.2008.10.020

Alvarez, M. D., \& Campo, S. (2014). The influence of political conflicts on country image and intention to visit: A study of Israel's image. Tourism Management, 40, 70-78. https://doi.org/10.1016/j.tourman.2013.05.009

Baloglu, S., \& McCleary, K. W. (1999). A model of destination image formation. Annals of Tourism Research, 26(4), 868-897. https://doi.org/10.1016/S0160-7383(99)00030-4

Beeton, S. (2001). Smiling for the camera: The influence of film audiences on a budget tourism destination. Tourism Culture \& Communication, 3(1), 15-25. https://doi.org/10.3727/109830401108750661

Bhattacherjee, A., \& Sanford, C. (2006). Influence processes for information technology acceptance: An elaboration likelihood model. MIS quarterly, 805-825. https://doi.org/10.2307/25148755

Bigné, J. E., Andreu, L., \& Gnoth, J. (2005). The theme park experience: An analysis of pleasure, arousal and satisfaction. Tourism Management, 26(6), 833-844. https://doi.org/10.1016/j.tourman.2004.05.006

Busby, G., \& Klug, J. (2001). Movie-induced tourism: The challenge of measurement and other issues. Journal of vacation marketing, 7(4), 316-332. https://doi.org/10.1177/135676670100700403

Chin, W. W., Marcolin, B. L., \& Newsted, P. R. (2003). A partial least squares latent variable modeling approach 
for measuring interaction effects: Results from a Monte Carlo simulation study and an electronic-mail emotion/adoption study. Information Systems Research, 14(2), 189-217. https://doi.org/10.1287/isre.14.2.189.16018

Choi, J. G., Tkachenko, T., \& Sil, S. (2011). On the destination image of Korea by Russian tourists. Tourism Management, 32(1), 193-194. https://doi.org/10.1016/j.tourman.2009.12.002

CNNIC. (2017). Research report on Chinese social application user behavior of 2016. Retrieved from http://www.cnnic.cn/hlwfzyj/hlwxzbg/sqbg/201712/t20171227_70118.htm

CNNIC. (2019). The 43rd Statistical Report on Internet Development in China. Retrieved from http://www.cnnic.net.cn/hlwfzyj/hlwxzbg/hlwtjbg/201902/t20190228_70645.htm

Cohen, J. (2013). Statistical power analysis for the behavioral sciences. Routledge.

Connell, J., \& Meyer, D. (2009). Balamory revisited: An evaluation of the screen tourism destination-tourist nexus. Tourism Management, 30(2), 194-207. https://doi.org/10.1016/j.tourman.2008.06.001

Crompton, J. L. (1979). An assessment of the image of Mexico as a vacation destination and the influence of geographical location upon that image. Journal of travel research, 17(4), 18-23. https://doi.org/10.1177/004728757901700404

Fakeye, P. C., \& Crompton, J. L. (1991). Image differences between prospective, first-time, and repeat visitors to the Lower Rio Grande Valley. Journal of travel research, 30(2), 10-16. https://doi.org/10.1177/004728759103000202

Fornell, C., \& Bookstein, F. L. (1982). Two structural equation models: LISREL and PLS applied to consumer

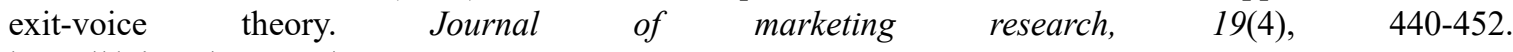
https://doi.org/10.1177/002224378201900406

Fornell, C., \& Larcker, D. F. (1981). Evaluating structural equation models with unobservable variables and

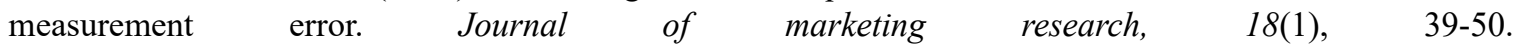
https://doi.org/10.1177/002224378101800104

Gefen, D., Straub, D., \& Boudreau, M.-C. (2000). Structural equation modeling and regression: Guidelines for research practice. Communications of the association for information systems, 4(1), 7. https://doi.org/10.17705/1CAIS.00407

Guo, Z., Huang, J., He, J., Hei, X., \& Wu, D. (2013). Unveiling the patterns of video tweeting: A sina weibo-based measurement study. Paper presented at the International Conference on Passive and Active Network Measurement.

Hair Jr, J. F., Sarstedt, M., Hopkins, L., \& Kuppelwieser, V. G. (2014). Partial least squares structural equation modeling (PLS-SEM) An emerging tool in business research. European Business Review, 26(2), 106-121. https://doi.org/10.1108/EBR-10-2013-0128

Hair, J. F., Ringle, C. M., \& Sarstedt, M. (2013). Partial least squares structural equation modeling: Rigorous applications, better results and higher acceptance. Long range planning, 46(1-2), 1-12. https://doi.org/10.1016/j.lrp.2013.01.001

Hallmann, K., Zehrer, A., \& Müller, S. (2015). Perceived destination image: An image model for a winter sports destination and its effect on intention to revisit. Journal of travel research, 54(1), 94-106. https://doi.org/10.1177/0047287513513161

Han, H., Lee, S., \& Lee, C. K. (2011). Extending the Theory of Planned Behavior: Visa Exemptions and the Traveller Decision-making Process. Tourism Geographies, 13(1), 45-74. https://doi.org/10.1080/14616688.2010.529930

Henseler, J., Ringle, C. M., \& Sarstedt, M. (2015). A new criterion for assessing discriminant validity in variance-based structural equation modeling. Journal of the academy of marketing science, 43(1), 115-135. https://doi.org/10.1007/s11747-014-0403-8

Hoffman, D. L., \& Novak, T. P. (1996). Marketing in hypermedia computer-mediated environments: Conceptual foundations. Journal of marketing, 60(3), 50-68. https://doi.org/10.1177/002224299606000304

Hosany, S., \& Martin, D. (2012). Self-image congruence in consumer behavior. Journal of Business Research, 65(5), 685-691. https://doi.org/10.1016/j.jbusres.2011.03.015

Hosany, S., Ekinci, Y., \& Uysal, M. (2006). Destination image and destination personality: An application of 
branding theories to tourism places. Journal of Business Research, 59(5), 638-642. https://doi.org/10.1016/j.jbusres.2006.01.001

Hsu, H.-Y., \& Tsou, H. T. (2011). The effect of website quality on consumer emotional states and repurchases intention. African Journal of Business Management, 5(15), 6194-6199. https://doi.org/10.5897/AJBM10.1573

Kim, J., \& Lennon, S. J. (2013). Effects of reputation and website quality on online consumers' emotion, perceived risk and purchase intention: Based on the stimulus-organism-response model. Journal of Research in Interactive Marketing, 7(1), 33-56. https://doi.org/10.1108/17505931311316734

Kim, S., Long, P., \& Robinson, M. (2009). Small screen, big tourism: The role of popular Korean television dramas in South Korean tourism. Tourism Geographies, 11(3), 308-333. https://doi.org/10.1080/14616680903053334

Kock, F., Josiassen, A., \& Assaf, A. G. (2016). Advancing destination image: The destination content model. Annals of Tourism Research, 61, 28-44. https://dx.doi.org/10.1016/j.annals.2016.07.003

Lai, K., \& Wang, D. (2009). A measurement study of external links of YouTube. Paper presented at the GLOBECOM 2009-2009 IEEE Global Telecommunications Conference.

Lee, S., \& Bai, B. (2010). A qualitative analysis of the impact of popular culture on destination image: A case study of Korean wave from Japanese fans.

Liu, L., Suh, A., \& Wagner, C. (2016). Watching online videos interactively: the impact of media capabilities in Chinese Danmaku video sites. Chinese Journal of Communication, 9(3), 283-303. https://doi.org/10.1080/17544750.2016.1202853

Mao, I. Y., \& Zhang, H. Q. (2014). Structural relationships among destination preference, satisfaction and loyalty in Chinese tourists to Australia. International Journal of Tourism Research, 16(2), 201-208. https://doi.org/10.1002/jtr.1919

McMillan, S. J., \& Hwang, J.-S. (2002). Measures of perceived interactivity: An exploration of the role of direction of communication, user control, and time in shaping perceptions of interactivity. Journal of advertising, 31(3), 29-42. https://doi.org/10.1080/00913367.2002.10673674

Mehrabian, A., \& Russell, J. A. (1974). An approach to environmental psychology. Cambridge, MA: The MIT Press.

Molinillo, S., Liébana-Cabanillas, F., Anaya-Sánchez, R., \& Buhalis, D. (2018). DMO online platforms: Image and intention to visit. Tourism Management, 65, 116-130. https://doi.org/10.1016/j.tourman.2017.09.021

Riley, R., Baker, D., \& Van Doren, C. S. (1998). Movie induced tourism. Annals of Tourism Research, 25(4), 919-935. https://doi.org/10.1016/S0160-7383(98)00045-0

Russell, J. A. (1978). Evidence of convergent validity on the dimensions of affect. Journal of personality and social psychology, 36(10), 1152. https://doi.org/10.1037/0022-3514.36.10.1152

Russell, J. A., \& Pratt, G. (1980). A description of the affective quality attributed to environments. Journal of personality and social psychology, 38(2), 311. https://doi.org/10.1037/0022-3514.38.2.311

Spencer, D. M. (2013). Effectiveness of intra-destination television advertising of tourist attractions and facilities. Journal of Destination Marketing \& Management, 2(3), 155-164. https://doi.org/10.1016/j.jdmm.2013.05.003

Steuer, J. (1992). Defining virtual reality: Dimensions determining telepresence. Journal of communication, 42(4), 73-93. https://doi.org/10.1111/j.1460-2466.1992.tb00812.x

Stylos, N., \& Andronikidis, A. (2013). Exploring the cognitive image of a tourism destination. Tourismos, 8(3).

Stylos, N., Vassiliadis, C. A., Bellou, V., \& Andronikidis, A. (2016). Destination images, holistic images and personal normative beliefs: Predictors of intention to revisit a destination. Tourism Management, 53, 40-60. https://doi.org/10.1016/j.tourman.2015.09.006

Tessitore, T., Pandelaere, M., \& Van Kerckhove, A. (2014). The Amazing Race to India: Prominence in reality television affects destination image and travel intentions. Tourism Management, 42, 3-12. https://doi.org/10.1016/j.tourman.2013.10.001

Wangpipatwong, S., Chutimaskul, W., \& Papasratorn, B. (2008). Understanding Citizen's Continuance Intention to Use e-Government Website: a Composite View of Technology Acceptance Model and Computer 
Self-Efficacy. Electronic Journal of e-Government, 6(1).

Wong, K. (2016). How Millennials And Gen Z Transformed Tourism Marketing Through Sharing. Retrieved from

https://www.forbes.com/sites/kylewong/2016/12/13/how-millennials-and-gen-z-transformed-tourism-marke ting-through-sharing/\#7d8b11772868

Woodside, A. G., \& Dubelaar, C. (2002). A general theory of tourism consumption systems: A conceptual framework and an empirical exploration. Journal of travel research, 41(2), 120-132. https://doi.org/10.1177/004728702237412

Wu, G. (2006). Conceptualizing and measuring the perceived interactivity of websites. Journal of Current Issues \& Research in Advertising, 28(1), 87-104. https://doi.org/10.1080/10641734.2006.10505193

Yun, Z.-S., \& Good, L. K. (2007). Developing customer loyalty from e-tail store image attributes. Managing Service Quality: An International Journal, 17(1), 4-22. https://doi.org/10.1108/09604520710720647

Zhang, H., Fu, X., Cai, L. A., \& Lu, L. (2014). Destination image and tourist loyalty: A meta-analysis. Tourism Management, 40, 213-223. https://doi.org/10.1016/j.tourman.2013.06.006

Zhang, X., Wu, Y., \& Liu, S. (2019). Exploring short-form video application addiction: Socio-technical and attachment perspectives. Telematics and Informatics, 101243. https://doi.org/10.1016/j.tele.2019.101243

Zhao, L., \& Lu, Y. (2012). Enhancing perceived interactivity through network externalities: An empirical study on micro-blogging service satisfaction and continuance intention. Decision Support Systems, 53(4), 825-834. https://doi.org/10.1016/j.dss.2012.05.019

\section{Copyrights}

Copyright for this article is retained by the author(s), with first publication rights granted to the journal.

This is an open-access article distributed under the terms and conditions of the Creative Commons Attribution license (http://creativecommons.org/licenses/by/4.0/). 